\title{
BILANGAN DOMINASI LOKASI PADA PAN GRAPH
}

\author{
Elishabet Yohana, Yundari, Fransiskus Fran
}

\section{INTISARI}

\begin{abstract}
Diberikan graf $G=(V, E)$ merupakan graf terhubung dan tak berarah. Himpunan $D \subseteq V$ merupakan himpunan dominasi lokasi jika untuk setiap simpul $u, v \in V-D$ dengan $u \neq v$ memenuhi $N(v) \cap D \neq$ $N(u) \cap D \neq \emptyset$. Bilangan dominasi lokasi dari graf $G$ dinotasikan dengan $\gamma_{L}(G)$ merupakan kardinalitas minimum dari himpunan dominasi lokasi pada graf $G$. Pada penelitian ini dibahas tentang bilangan dominasi lokasi pada graf lintasan $\left(P_{n}\right)$, graf cycle $\left(C_{n}\right)$ dan pan graph $\left(T_{n, 1}\right)$. Langkah-langkah yang dilakukan dalam penelitian ini adalah mencari himpunan dominasi lokasi dari masing-masing graf, kemudian mencari satu persatu bilangan dominasi lokasi pada setiap graf tersebut. Pada tahap akhir, diperoleh pola bilangan dominasi lokasi pada masing-masing graf. Berdasarkan hasil penelitian, diperoleh $\gamma_{L}\left(P_{n}\right)=\left\lceil\frac{2 n}{5}\right\rceil ; \gamma_{L}\left(C_{n}\right)=\left\lceil\frac{2 n}{5}\right\rceil$ dan $\gamma_{L}\left(T_{n, 1}\right)$ untuk $n=3$ yaitu 2 , untuk $n=4$ yaitu 3 , untuk $n \geq 5$ yaitu $\left\lfloor\frac{2 n}{5}\right\rfloor+1$.
\end{abstract}

Kata kunci: himpunan dominasi lokasi, graf cycle, graf lintasan

\section{PENDAHULUAN}

Salah satu topik yang dibahas dalam teori graf adalah himpunan dominasi. Himpunan $D \subseteq V(G)$ disebut himpunan dominasi jika simpul pada himpunan dominasi tersebut mendominasi semua simpul di $G$. Terdapat beberapa topik mengenai himpunan dominasi diantaranya yaitu himpunan dominasi edge-vertex, himpunan dominasi vertex-edge, himpunan dominasi total, himpunan dominasi lokasi, himpunan dominasi invers dan lain sebagainya. Salah satu topik himpunan dominasi yang dibahas dalam penelitian ini adalah himpunan dominasi lokasi. Himpunan dominasi lokasi pada graf $G$ adalah himpunan dominasi graf $G$ dengan syarat untuk setiap $u, v \in V-D$ berlaku $N(u) \cap D \neq N(v) \cap D \neq$ $\emptyset$ dengan $N(u)$ merupakan persekitaran terbuka $u$. Bilangan dominasi lokasi pada graf $G$ dinotasikan dengan $\gamma_{L}(G)$ merupakan kardinalitas minimum dari himpunan dominasi lokasi [1]. Penelitian yang membahas bilangan dominasi lokasi, telah diterapkan pada graf lintasan dan graf cycle [2]. Pada penelitian ini dikaji ulang mengenai bilangan dominasi lokasi pada graf lintasan dan graf cycle yang sebelumnya telah diteliti. Selain itu, dilakukan penelitian lebih lanjut untuk mengembangkan penelitian sebelumnya yaitu mengenai pan graph.

\section{PAN GRAPH}

Graf $G$ didefinisikan sebagai pasangan himpunan $(V, E)$, ditulis dengan notasi $G=(V, E)$, yang dalam hal ini $V$ adalah himpunan tidak-kosong dari simpul (vertex) dan $E$ adalah himpunan sisi (edge) yang menghubungkan sepasang simpul. Sebuah graf dimungkinkan tidak mempunyai sisi satu buah pun, tetapi simpulnya harus ada, minimal satu [3].

Beberapa terminologi dasar yang berkaitan dengan teori graf yang digunakan dalam penelitian ini yaitu bertetangga, terhubung dan persekitaran simpul. Simpul $u$ dan simpul $v$ pada suatu graf tak berarah $G$ dikatakan bertetangga apabila kedua simpul tersebut dihubungkan langsung oleh sebuah sisi $e=(u, v)$ [3]. Suatu graf tak-berarah $G$ disebut graf terhubung jika untuk setiap pasang simpul $u$ dan simpul $v$ didalam himpunan $V$ terdapat lintasan dari $u$ ke $v$. Jika tidak, maka $G$ disebut graf takterhubung [3]. Himpunan $N(u)=\{v \in V(G): u v \in E(G)\}$ disebut persekitaran terbuka dari $u$ pada graf $G$ dan himpunan $N[u]=N(u) \cup\{u\}$ disebut persekitaran tertutup dari $u$ pada graf $G$ [4]. Graf 
dapat dikelompokkan menjadi beberapa jenis, beberapa jenis graf yang digunakan dalam penelitian ini adalah graf lintasan $P_{n}$, graf cycle $C_{n}$ dan pan graph $T_{n, 1}$. Berikut definisi terkait graf-graf tersebut.

Definisi 1 [5] Graf lintasan adalah suatu graf sederhana yang terdiri dari satu lintasan tunggal. Graf lintasan dengan $n$ simpul dinotasikan dengan $P_{n}$ dengan $n \geq 2$.

Definisi 2 [3] Graf cycle merupakan graf sederhana yang setiap simpulnya berderajat dua. Graf cycle dengan $n$ simpul dilambangkan dengan $C_{n}$ untuk $n \geq 3$

Definisi 3 [6] Pan graph adalah graf yang diperoleh dengan menggabungkan graf cycle $C_{n}$ dan graf tunggal $K_{1}$ dengan sisi sebagai penghubung.

Pada penelitian ini, pan graph dinotasikan dengan $T_{n, 1}$ [7].

Bentuk graf lintasan, graf cycle dan pan graph dapat dilihat pada Gambar 1.

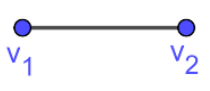

(a)

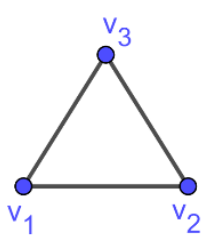

(b)

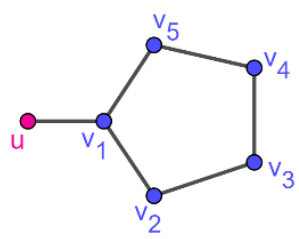

(c)

\section{Gambar 1 (a) Graf Lintasan $P_{2}$, (b) Graf Cycle $C_{3}$ dan (c) Pan Graph $T_{5,1}$}

Pada Gambar 1 (a) graf lintasan $P_{2}$ terdiri dari 2 simpul dan 1 sisi dengan barisan berselangseling antara simpul-simpul dan sisi-sisi yang berbentuk $v_{1}, e_{1}, v_{2}$. Gambar 1 (b) graf cycle $C_{3}$ merupakan graf dengan himpunan simpul $V\left(C_{3}\right)=\left\{v_{1}, v_{2}, v_{3}\right\}$ dan setiap simpul pada graf cycle $C_{3}$ memiliki derajat 2. Gambar 1 (c) pan graph $T_{5,1}$ merupakan graf yang terdiri dari enam simpul dengan himpunan simpul $V\left(T_{5,1}\right)=\left\{u, v_{1}, v_{2}, v_{3}, v_{4}, v_{5}\right\}$. Simpul $u$ merupakan elemen dari graf tunggal $K_{1}$ dan simpul $v_{i}$ dengan $i=1,2,3,4,5$ merupakan simpul-simpul pada graf cycle $C_{5}$.

\section{BILANGAN DOMINASI LOKASI}

Secara historis, masalah dominasi mulai dipelajari dari tahun 1960 oleh Hedetniemi dan Laskar. Himpunan $D \subseteq V(G)$ disebut himpunan dominasi jika simpulnya mendominasi semua simpul di $G$ [8]. Terdapat beberapa topik mengenai himpunan dominasi salah satunya yaitu himpunan dominasi lokasi. Penerapan himpunan dominasi lokasi dimulai pada tahun 1980 oleh Slater dengan membuat sebuah kode lokasi perlindungan untuk beberapa fasilitas dengan menggunakan jaringan detektor. Pada tahun 2016 penerapan himpunan dominasi lokasi kembali dikembangkan oleh Foucaud, Mertzios, Parreau, Naserasr dan Vallicov yaitu menerapkan himpunan dominasi lokasi dalam kasus penempatan alat deteksi kebakaran pada suatu gedung [9].

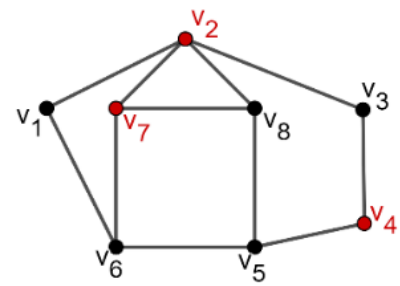

Gambar 2 Himpunan Dominasi Graf $\boldsymbol{H}$ 
Definisi 4 [1] Himpunan dominasi lokasi pada graf $G$ adalah himpunan dominasi graf $G$ dengan syarat untuk setiap $u, v \in V-D$ dengan $u \neq v$ berlaku $N(u) \cap D \neq N(v) \cap D \neq \emptyset$. Kardinalitas minimum dari himpunan dominasi lokasi graf $G$ disebut bilangan dominasi lokasi dan dinotasikan dengan $\gamma_{L}(G)$.

Contoh 5 Diberikan graf $H$ seperti pada Gambar 2.

Pada Gambar 2 dapat dipilih beberapa kemungkinan himpunan dominasi pada graf $H$ yaitu $\left\{v_{2}, v_{4}, v_{7}\right\},\left\{v_{4}, v_{6}, v_{8}\right\},\left\{v_{2}, v_{3}, v_{5}, v_{8}\right\}$ dan $\left\{v_{1}, v_{3}, v_{5}, v_{7}\right\}$. Berdasarkan beberapa kemungkinan tersebut, dapat ditentukan bilangan dominasi lokasi dari graf $H$ adalah tiga.

\section{Bilangan Dominasi Lokasi pada Graf Lintasan $\boldsymbol{P}_{\boldsymbol{n}}$}

Bilangan dominasi lokasi pada graf lintasan $P_{n}$ untuk $n \geq 2$ disajikan pada Proposisi 6 .

Proposisi 6 [2] Diberikan graf $G$ suatu graf lintasan $P_{n}$ yang merupakan lintasan tunggal dengan $n$ simpul, $n \in \mathbb{N}$. Bilangan dominasi lokasi pada graf $G$ adalah $\gamma_{L}\left(P_{n}\right)=\left\lceil\frac{2 n}{5}\right\rceil$ untuk $n \geq 2$.

Contoh 7 Diberikan graf lintasan $P_{4}$ seperti pada Gambar 3.

Pada Gambar 3, himpunan simpul dominasi untuk graf lintasan $P_{4}$ yaitu $D=\left\{v_{2}, v_{4}\right\}$ dan simpul selain simpul dominasinya yaitu $v_{1}$ dan $v_{3}$. Berdasarkan Gambar $3, N\left(v_{1}\right) \cap D \neq \varnothing$ dan $N\left(v_{3}\right) \cap D \neq$ $\emptyset$ yang artinya $D$ menjangkau semua simpul yang bukan termasuk simpul dominasi. Selain itu terlihat bahwa $N\left(v_{1}\right) \cap D \neq N\left(v_{3}\right) \cap D$ yanga artinya $D$ memenuhi syarat himpunan dominasi lokasi sehingga diperoleh $\gamma_{L}\left(P_{4}\right)=2$.

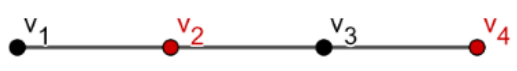

\section{Gambar 3 Graf Lintasan $P_{4}$}

\section{Bilangan Dominasi Lokasi pada Graf Cycle $\boldsymbol{C}_{\boldsymbol{n}}$}

Bilangan dominasi lokasi pada graf cycle $C_{n}$ untuk $n \geq 3$ disajikan pada Proposisi 8 .

Proposisi 8 [2] Diberikan graf $G$ suatu graf cycle $C_{n}$ dengan $n$ simpul yang setiap simpulnya berderajat $2, n \in \mathbb{N}$. Bilangan dominasi lokasi pada graf $G$ adalah $\gamma_{L}\left(C_{n}\right)=\left\lceil\frac{2 n}{5}\right\rceil$ untuk $n \geq 3$.

Contoh 9 Diberikan graf cycle $C_{4}$ seperti pada Gambar 4.

Pada Gambar 4, himpunan simpul dominasi untuk graf cycle $C_{4}$ yaitu $D=\left\{v_{1}, v_{4}\right\}$ dan simpul selain simpul dominasinya yaitu $v_{2}$ dan $v_{3}$. Berdasarkan Gambar $4, N\left(v_{2}\right) \cap D \neq \varnothing$ dan $N\left(v_{3}\right) \cap D \neq \varnothing$ yang artinya $D$ menjangkau semua simpul yang bukan termasuk simpul dominasi. Selain itu terlihat bahwa $N\left(v_{2}\right) \cap D \neq N\left(v_{3}\right) \cap D$ yanga artinya $D$ memenuhi syarat himpunan dominasi lokasi sehingga diperoleh $\gamma_{L}\left(C_{4}\right)=2$.

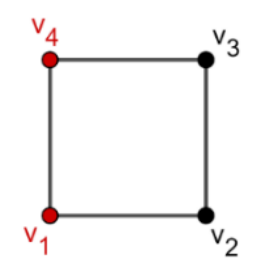

Gambar 4 Graf Cycle $C_{4}$ 


\section{Bilangan Dominasi Lokasi pada Pan Graph $T_{n, 1}$}

Berikut diberikan Proposisi 10 mengenai bilangan dominasi lokasi pada pan graph $T_{n, 1}$ untuk $n \geq 3$.

Proposisi 10 Pan graph $\left(T_{n, 1}\right)$ merupakan graf hasil penggabungan graf cycle $C_{n}$ dan graf tunggal $K_{1}$ dengan sebuah penghubung. Bilangan dominasi lokasi pada pan graph $\left(T_{n, 1}\right)$ adalah

$$
\gamma_{L}\left(T_{n, 1}\right)=\left\{\begin{array}{l}
2, n=3 \\
3, n=4 \\
\left\lfloor\frac{2 \mathrm{n}}{5}\right\rfloor+1, n \geq 5
\end{array}\right.
$$

Bukti: Diberikan pan graph $\left(T_{n, 1}\right)$ dengan $n \geq 3$. Himpunan simpul dari Pan graph $\left(T_{n, 1}\right)$ yaitu $V\left(T_{n, 1}\right)=\left\{v_{1}, v_{2}, \cdots, v_{n}, v_{n+1}\right\}$. Ambil $v_{i} \in V\left(T_{n, 1}\right)$ dengan $i=3,4,5, \cdots, n, n+1$ maka $v_{i}$ dapat mendominasi 2 simpul disekitarnya dan untuk $i=1$ mendominasi 1 simpul disekitarnya dan $i=2$ mendominasi 3 simpul disekitarnya.

Kasus 1: untuk $n=3$

Pada pan graph $\left(T_{3,1}\right)$ diperoleh himpunan dominasi yaitu $D_{1}=\left\{v_{2}, v_{4}\right\}$. Himpunan $V-D_{1}=$ $\left\{v_{1}, v_{3}\right\}$ pada pan graph $\left(T_{3,1}\right)$ berlaku $N\left(v_{1}\right) \cap D_{1} \neq N\left(v_{3}\right) \cap D_{1} \neq \varnothing$ sehingga $D_{1}=\left\{v_{2}, v_{4}\right\}$ merupakan himpunan dominasi lokasi pada pan graph $T_{3,1}$. Diperoleh banyaknya anggota pada himpunan $D_{1}$ adalah 2. Berdasarkan Definisi 4, maka bilangan dominasi lokasi pada pan graph $T_{3,1}$ haruslah memenuhi $\gamma_{L}\left(T_{3,1}\right) \leq 2$. Andaikan $\gamma_{L}\left(T_{3,1}\right)=1$, maka terdapat 1 simpul pada himpunan dominasi lokasi pan graph $\left(T_{3,1}\right)$ dengan kardinalitas minimum. Jika terdapat 1 simpul pada himpunan dominasi lokasi yang dipilih sembarang, maka 2 simpul elemen $V-D$ yaitu $v_{1}, v_{n+1} \in V-$ $D$ akan memiliki tetangga yang sama pada himpunan $D$. Hal tersebut kontradiksi dengan Definisi 4 , maka haruslah $\gamma_{L}\left(T_{3,1}\right)=2$.

Kasus 2: untuk $n=4$

Pada pan graph $\left(T_{4,1}\right)$ diperoleh himpunan dominasi yaitu $D_{2}=\left\{v_{2}, v_{4}, v_{5}\right\}$. Himpunan $V-D_{2}=$ $\left\{v_{1}, v_{3}\right\}$ pada pan graph $\left(T_{4,1}\right)$ berlaku $N\left(v_{1}\right) \cap D_{2} \neq N\left(v_{3}\right) \cap D_{2} \neq \varnothing$ sehingga $D_{2}=\left\{v_{2}, v_{4}, v_{5}\right\}$ merupakan himpunan dominasi lokasi pada pan graph $\left(T_{4,1}\right)$. Diperoleh banyaknya anggota pada himpunan $D_{2}$ adalah 3. Berdasarkan Definisi 4, maka bilangan dominasi lokasi pada pan graph $\left(T_{4,1}\right)$ haruslah memenuhi $\gamma_{L}\left(T_{4,1}\right) \leq 3$. Andaikan $\gamma_{L}\left(T_{4,1}\right)=2$, maka terdapat 2 simpul pada himpunan dominasi lokasi graf $\left(T_{4,1}\right)$ dengan kardinalitas minimum. Jika terdapat 2 simpul pada himpunan dominasi lokasi yang dipilih sembarang, maka 2 simpul elemen $V-D$ yaitu $v_{1}, v_{n+1} \in V-D$ akan memiliki tetangga yang sama pada himpunan $D$. Hal tersebut kontradiksi dengan Definisi 4 , maka haruslah $\gamma_{L}\left(T_{4,1}\right)=3$.

Kasus 3: untuk $n \geq 5$

Berdasarkan definisi himpunan dominasi diperoleh himpunan dominasi $\left(T_{n, 1}\right)$ untuk $n \geq 5$ yaitu:

(i) Untuk $n=5 k, k \in \mathbb{N}$ diperoleh himpunan dominasi yaitu $D_{3}=\left\{v_{1}\right\} \cup\left\{v_{3}, v_{6}, \cdots, v_{5\left[\frac{n}{5}\right\rfloor-2}, v_{5\left[\frac{n}{5}\right\rfloor+1}\right\}$

(ii) Untuk $n=5 k+1$ dan $n=5 k+2$ diperoleh himpunan dominasi yaitu $D_{4}=\left\{v_{2}\right\} \cup$ $\left\{v_{4}, v_{7}, \cdots, v_{5\left[\frac{n}{5}\right\rfloor-1}, v_{5\left[\frac{n}{5}\right\rfloor+2}\right\}$,

$$
\begin{aligned}
& \text { Untuk } n \text { lainnya diperoleh himpunan dominasi yaitu } \\
& D_{5}=\left\{v_{2}\right\} \cup\left\{v_{4}\right\} \cup\left\{v_{7}, v_{9}, \cdots, v_{5}\left|\frac{n}{5}\right|+2, v_{5}\left|\frac{n}{5}\right|+4\right\} .
\end{aligned}
$$

Setiap himpunan $D_{i}$ dengan $i=3,4,5$ memiliki indeks beda 2 atau beda 3 secara berurut antara indeks simpul yang satu dengan indeks simpul lainnya. 
Akibatnya, untuk $v_{a}, v_{b} \in V-D_{i}$ dengan $v_{a} \neq v_{b}$ diperoleh $N\left(v_{a}\right) \cap D_{i} \neq \emptyset$ dan $N\left(v_{b}\right) \cap D_{i} \neq \emptyset$. Berdasarkan himpunan $D_{i}$ dengan $i=3,4,5$ diketahui bahwa untuk setiap simpul diluar $D_{i}$ yaitu simpul $V-D_{i}$ memiliki indeks beda 1 atau beda 2 secara berurut antara simpul yang satu dengan simpul lainnya. Akibatnya, diperoleh $N\left(v_{a}\right) \cap D_{i} \neq N\left(v_{b}\right) \cap D_{i}$ untuk $v_{a}, v_{b} \in V-D_{i}$ dengan $v_{a} \neq v_{b}$. Berdasarkan Definisi 4, maka himpunan-himpunan dominasi tersebut memenuhi syarat himpunan dominasi lokasi. Berdasarkan himpunan-himpunan tersebut, indeks dari simpul $v_{i}$ dapat disusun menjadi barisan aritmatika sebagai berikut:

$$
\begin{aligned}
& D_{3}^{\prime}=\{1\} \cup\left\{6,11,16,21, \cdots, 5\left\lfloor\frac{n}{5}\right\rfloor+1\right\} \cup\left\{3,8,13,18, \cdots, 5\left\lfloor\frac{n}{5}\right\rfloor-2\right\} \\
& D_{4}^{\prime}=\{2\} \cup\left\{7,12,17,22, \cdots, 5\left\lfloor\frac{n}{5}\right\rfloor+2\right\} \cup\left\{4,9,14,19, \cdots, 5\left\lfloor\frac{n}{5}\right\rfloor-1\right\} \\
& D_{5}^{\prime}=\{2\} \cup\{4\} \cup\left\{7,12,17,22, \cdots, 5\left\lfloor\frac{n}{5}\right\rfloor+2\right\} \cup\left\{9,14,19,24, \cdots, 5\left\lfloor\frac{n}{5}\right\rfloor+4\right\}
\end{aligned}
$$

Banyaknya anggota dari setiap himpunan dapat diperoleh dengan menggunakan rumus barisan aritmatika dengan beda 5 antara suku pertama dan suku kedua sampai seterusnya secara berurut pada setiap himpunan. Diperoleh banyaknya anggota pada himpunan $D_{3}$ dan $D_{4}$ yaitu $1+\left\lfloor\frac{n}{5}\right\rfloor+\left\lfloor\frac{n}{5}\right\rfloor$ untuk $n=5 k$ dan $n=5 k+1$ dan banyaknya anggota pada himpunan $D_{5}$ yaitu $1+1+\left\lfloor\frac{n}{5}\right\rfloor+\left\lfloor\frac{n}{5}\right\rfloor$ untuk $n$ lainnya. Akibatnya diperoleh banyaknya anggota himpunan dominasi lokasi dari pan graph $\left(T_{n, 1}\right)$ dengan $n \geq 5$ adalah $\left\lfloor\frac{2 n}{5}\right\rfloor+1$. Berdasarkan Definisi 4, maka bilangan dominasi lokasi haruslah memenuhi $\gamma_{L}\left(T_{n, 1}\right) \leq\left\lfloor\frac{2 n}{5}\right\rfloor+1$ dengan $n \geq 5$. Selanjutnya, akan ditunjukkan bilangan dominasi lokasi pada pan graph $\left(T_{n, 1}\right)$ dengan $n \geq 5$ adalah $\gamma_{L}\left(T_{n, 1}\right)=\left\lfloor\frac{2 n}{5}\right\rfloor+1$. Menurut Definisi 4 , himpunan dominasi lokasi harus memenuhi syarat untuk setiap $v_{a}, v_{b} \in V-D_{i}$ dengan $v_{a} \neq v_{b}$ berlaku $N\left(v_{a}\right) \cap D_{i} \neq N\left(v_{b}\right) \cap D_{i} \neq \varnothing$. Andaikan $\gamma_{L}\left(T_{n, 1}\right)=\left(\left\lfloor\frac{2 \mathrm{n}}{5}\right\rfloor+1\right)-1$, maka terdapat $\left\lfloor\frac{2 \mathrm{n}}{5}\right\rfloor$ simpul pada himpunan dominasi lokasi graf $\left(T_{n, 1}\right)$ untuk $n \geq 5$ dengan kardinalitas minimum. Jika terdapat $\left\lfloor\frac{2 n}{5}\right\rfloor$ simpul pada himpunan dominasi lokasi yang dipilih sembarang, dapat dipilih pada simpul yang mendominasi paling minimum yaitu 1 simpul disekitarnya sampai yang paling maksimum 3 simpul sekitarnya. Akibatnya untuk $T_{n, 1}$ dengan $n \geq 5$ terdapat setidaknya dua simpul yang berbeda yaitu $v_{1}, v_{n+1} \in V-D$ yang memiliki tetangga yang sama di $D$ dan untuk $T_{7,1}$ terdapat satu simpul tidak terdominasi. Hal tersebut kontradiksi dengan Definisi 4, maka haruslah $\gamma_{L}\left(T_{n, 1}\right)=$ $\left\lfloor\frac{2 n}{5}\right\rfloor+1$ untuk $n \geq 5$.

Dari ketiga kasus tersebut maka terbukti bahwa bilangan dominasi lokasi pada pan graph adalah

$\gamma_{L}\left(T_{n, 1}\right)=\left\{\begin{array}{c}2, n=3 \\ 3, n=4 \\ \left\lfloor\frac{2 \mathrm{n}}{5}\right\rfloor+1, n \geq 5\end{array}\right.$.

Contoh 11 Diberikan pan graph $T_{4,1}$ seperti pada Gambar 5.

Pada Gambar 5 (a), himpunan simpul dominasi untuk pan graph $T_{3,1}$ yaitu $D_{1}=\left\{v_{2}, v_{4}\right\}$ dan simpul selain simpul dominasinya yaitu $v_{1}$ dan $v_{3}$. Berdasarkan Gambar 5 (a), $N\left(v_{1}\right) \cap D_{1} \neq N\left(v_{3}\right) \cap D_{1} \neq$ $\varnothing$ yang artinya $D_{1}$ memenuhi syarat himpunan dominasi lokasi sehingga diperoleh $\gamma_{L}\left(T_{3,1}\right)=2$. Dengan cara yang sama, diperoleh himpunan dominasi lokasi dari pan graph $T_{4,1}$ yaitu $D_{2}=$ $\left\{v_{2}, v_{4}, v_{5}\right\}$ pada Gambar 5 (b) sehingga diperoleh $\gamma_{L}\left(T_{4,1}\right)=3$. 


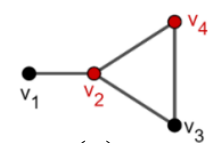

(a)

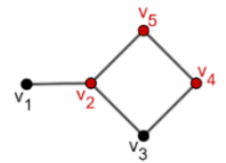

(b)

Gambar 5 (a) Pan Graph $T_{3,1}$ dan (b) Pan Graph $T_{4,1}$

\section{KESIMPULAN}

Bilangan dominasi lokasi merupakan kardinalitas minimum dari himpunan dominasi lokasi. Bilangan dominasi lokasi pada graf lintasan, graf cycle dan pan graph diperoleh dengan cara mencari himpunan dominasi lokasi masing-masing graf, selanjutnya mencari satu persatu bilangan dominasi lokasi pada setiap graf tersebut. Pada tahap akhir, diperoleh pola bilangan dominasi lokasi pada masing-masing graf. Pada penelitian ini diperoleh bilangan dominasi lokasi pada beberapa graf yaitu graf lintasan adalah $\gamma_{L}\left(P_{n}\right)=\left\lceil\frac{2 n}{5}\right\rceil$ dengan $n \geq 2$, bilangan dominasi lokasi pada graf cycle adalah $\gamma_{L}\left(C_{n}\right)=\left\lceil\frac{2 n}{5}\right\rceil$ dengan $n \geq 3$ dan bilangan dominasi lokasi pada pan graph adalah $\gamma_{L}\left(T_{n, 1}\right)=\left\{\begin{array}{l}2, n=3 \\ 3, n=4 \\ {\left[\frac{2 n}{5}\right]+1, n \geq 5}\end{array}\right.$.

\section{DAFTAR PUSTAKA}

[1] Chellali M, Mimouni M dan Slater PJ. On Locating-Domination in Graphs. Discussiones Mathematicae Graph Theory. 2010; 30:223-235.

[2] Hernando C, Mora M dan Pelayo M. Locating Domination in Bipartite Graphs and Their Complements. Departament de Matematiques. 2018; 2:1-15.

[3] Munir R. Matematika Diskrit Ed-3. Bandung: Informatika; 2010.

[4] Murtaza M, Fazil M, Javaid I dan Benish H. Locating-Dominating Set of Functigraphs. Mathematics Subject Classification. 2017;1:1-14.

[5] Damayanti TR. Automorfisme Graf Bintang dan Graf Lintasan, Jurnal Cauchy. 2011; 2:20860382.

[6] Siddiqui N dan James M. Domination and Chromatic Number of Pan Graph and Lollipop Graph. International Journal of Technical Innovation in Modern Engineering \& Science (IJTIMES). 2018; 4:932-939.

[7] Ayhan AK dan Omar AK. Determination and Testing the Domination Numbers of Tadpole Graph, Book Graph and Stacked Book Graph Using MATLAB. College of Basic Education Researchers Journal. 2010; 10(1):491-504.

[8] Huang J dan Xu JM. Domination and Total Domination Contraction Number of Graphs. Ars Combinatoria. 2010; 94:431-443.

[9] Foucaud F, Mertzios GB, Naserasr R, Parreau A dan Valicov P. Identification, LocationDomination and Metric Dimension Interval and Permutation Graphs. II. Algorithms and Complexity. Algorithmica. 2016; 78(3): 914-944.

ELISHABET YOHANA : Jurusan Matematika FMIPA UNTAN, Pontianak elishabetyohana@gmail.com

YUNDARI : Jurusan Matematika FMIPA UNTAN, Pontianak yundari@math.untan.ac.id

FRANSISKUS FRAN $\quad$ J Jurusan Matematika FMIPA UNTAN, Pontianak fransiskusfran@math.untan.ac.id 